\title{
Recent advances and perspectives in crop biofortification
}

\author{
T. VLČKO and L. OHNOUTKOVÁ* \\ Laboratory of Growth Regulators, Palacký University \& Institute of Experimental Botany, Czech Academy of \\ Sciences, Šlechtiteli 241/27, 78371 Olomouc, Czech Republic
}

\begin{abstract}
The increasing world population and limited amount of land area appropriate for intensive agriculture necessitate highyield cultivars. The focus is on the enrichment of existing crops deficient in nutrients, which is also called biofortification. Microelements, vitamins, and fatty acids belong to most important traits being subjected to biofortification. Biofortification strategies can be divided on fertilization-based strategy, which is characterized by direct application of nutrients or plant growth promoting substances on plants, and biotechnological strategy, which involves molecular biology techniques in order to enhance transport, production, and accumulation of nutrients. Recent advances in plant biotechnology, such as genome-editing, clustered regularly interspaced short palindromic repeats (CRISPR)/CRISPR-associated 9 (Cas9), and transcription activator-like effector nuclease (TALEN), as well as an extensive study of genetic diversity, are acceptable approaches to the development of biofortified crops.
\end{abstract}

Additional key words: gene-editing, programmable nucleases, RNA interference.

\section{Introduction}

Crop biofortification is the process of plant seed enrichment with nutritionally important substances (Bouis 2002). Attempts to biofortify crops have been conducted in order to meet demands of the mineral and vitamins for humans in populations under conditions of limited food sources. Prominent crops that have been subjected to biofortification efforts in recent years are: wheat (Singh et al. 2017), barley (Sikdar et al. 2016), maize (Zhu et al. 2008, Du et al. 2016), rice (Johnson et al. 2011, Lee et al. 2011, Ma et al. 2015, Yang et al. 2016), sorghum (Che et al. 2016), and banana (Paul et al. 2017); all serving as staple food sources in large areas of the world. Microelements, vitamins, and fatty acids (FAs) constitute the main groups of substances that were subjected to biofortification (Table 1). With regard to the current state of technology and knowledge, biofortification of crops can be achieved in two ways: 1) fertilization-based and 2) biotechnological approaches (Fig. 1). Fertilizationbased approaches cover an area from direct fertilization by nutrients to stimulate better plant growth and interaction with soil microorganisms, whereas biotechnological approaches rely on application of molecular biology techniques and recombinant technology. The aim of this review is to analyze the advances in methods used for crop biofortification, which have been developed in recent years, and to shed light on the means of applying the current techniques.

\section{Fertilization based approaches}

These approaches precede biotechnological because of simplicity of practical application. Application of fertilizers belongs to first attempts that have been adapted for the

Submitted 26 October 2018, last revision 6 February 2019, accepted 20 February 2019.

Abbreviations: AA - amino acids; Cas9 - CRISPR-associated 9; CRISPR - clustered regularly interspaced short palindromic repeats; dapA - dihydrodipicolinate synthase; FA - fatty acid; FAD - fatty acid dehydrogenase; FAE - fatty acid elongase; GS-MAS - markerassisted selection based on genomic selection; HGO - homogentisate dioxygenase; LKR - lysine ketoglutarate reductase; lysC - lysine feedback-insensitive aspartate kinase; LOX - lipoxygenase; MAS - marker-assisted selection; NAS - nicotianamine synthase; QTL quantitative trait locus; RNAi - RNA interference; SAD1 - stearoyl-acyl carrier protein desaturase-1; SDH - saccharopine dehydrogenase; TALEN - transcription activator-like effector nuclease.

Acknowledgements: This work was supported by GACR project No. 15-22276S and by the European Regional Development Fund Project, Centre for Experimental Plant Biology, No. CZ.02.1.01/0.0/0.0/16_019/0000738. The authors would like to thank Peter Lemkin for the English corrections.

* Corresponding author; e-mail: ludmila.ohnoutkova@upol.cz 
Table 1. Biofortified traits in important crops.

\begin{tabular}{|c|c|c|c|}
\hline Trait & Crop & Technique & Reference \\
\hline \multicolumn{4}{|l|}{ Micro-, macro-elements } \\
\hline $\mathrm{Zn}$ and $\mathrm{Fe}$ & Triticum aestivum & over-expression of Osnas 2 & Singh et al. 2017 \\
\hline $\mathrm{Zn}$ & Triticum aestivum & P fertilization & Zhang et al. 2015 \\
\hline $\mathrm{Zn}, \mathrm{Mg}, \mathrm{Mn}$ & Triticum aestivum & Se fertilization & Boldrin et al. 2016 \\
\hline $\mathrm{Zn}, \mathrm{Fe}, \mathrm{N}, \mathrm{P}, \mathrm{K}$ & Triticum aestivum & inoculation by rhizobacteria & Shaikh and Saraf 2017 \\
\hline $\mathrm{Zn}$ & Hordeum vulgare & over-expression of Hvzip 7 & Tiong et al. 2014 \\
\hline $\mathrm{Zn}$ & Hordeum vulgare & Zn fertilization & Uddin et al. 2014 \\
\hline $\mathrm{Zn}$ and $\mathrm{Fe}$ & Oryza sativa & over-expression of Osnas 1 and Osnas2 & Johnson et al. 2011 \\
\hline $\mathrm{Zn}$ & Oryza sativa & over-expression of Osnas 2 & Lee et al. 2011 \\
\hline $\mathrm{Zn}$ & Oryza sativa & over-expression of Osnas 2 & Moreno-Moyano et al. 2016 \\
\hline $\mathrm{Fe}$ & Oryza sativa & over-expression of Atirt1, Atnas 1, Pvfer & Boonyaves et al. 2017 \\
\hline $\mathrm{N}, \mathrm{S}, \mathrm{K}, \mathrm{P}$ & Brassica napus & biostimulant application & Billard et al. 2014 \\
\hline I & Lactuca sativa & $\mathrm{KI}$ and $\mathrm{KIO}_{3}$ foliar application & Lawson et al. 2016 \\
\hline \multicolumn{4}{|l|}{ Vitamins and antioxidants } \\
\hline Carotenoids & Zea mays & $\begin{array}{l}\text { over-expression of Zmpsy1, Pacrtl, Gllycb, } \\
\text { Glbch, ParacrtW }\end{array}$ & Zhu et al. 2008 \\
\hline Carotenoids & Musa acuminata & Mtpsy2a, Zmpsy1, Pacrtl & Paul et al. 2017 \\
\hline Vitamin $\mathrm{B}_{9}$ & Oryza sativa & over-expression of adcs, gtpchi, $f b p$ & Blancquaert et al. 2015 \\
\hline Vitamin $B_{1}$ & Allium сера & arbuscular-mycorrhizal fungi & Rozpadek et al. 2016 \\
\hline $\begin{array}{l}\beta \text {-carotene } \\
\text { Vitamin E }\end{array}$ & Sorghum bicolor & $\begin{array}{l}\text { over-expression of psyl, crt1, At-dxs, pmi, } \\
\text { hggt }\end{array}$ & Che et al. 2016 \\
\hline \multicolumn{4}{|l|}{ Aminoacids } \\
\hline Amino acids & Hordeum vulgare & silencing Chordein & Sikdar et al. 2016 \\
\hline Lysine & Oryza sativa & $\begin{array}{l}\text { over-expression of } d a p A \text { and } l y s C \text { and } \\
\text { silencing } l k r \text { and } s d h\end{array}$ & Yang et al. 2016 \\
\hline \multicolumn{4}{|l|}{ Fatty acids } \\
\hline Fatty acids & Oryza sativa & mutagenesis in Oslox 3 & Ma et al. 2015 \\
\hline $\begin{array}{l}\omega 3 \text { polyunsaturated fatty } \\
\text { acids }\end{array}$ & Camelina sativa & $\begin{array}{l}\text { over-expression of pse1, Tc } \Delta 5 \text {, Ot } \Delta 6, \text { Piw3, } \\
\text { Ps } \Delta 12 \text {, Otelo5, Eh } 44\end{array}$ & Ruiz-Lopez et al. 2014 \\
\hline
\end{tabular}

agricultural practice in order to enhance crop production. Conventional biofortification strategies mostly focusing on microelement enhancement are based on the application of elements as a constituent part of fertilizers applied: onto the leaves (foliar application); directly into the soil; or into the nutrient solution in the case of hydroponic cultures. The indisputable advantage of the conventional approach is the simplicity of the procedure in terms of the technical requirements, and it also obviates the legislative obstacles of genetically modified organism (GMO) techniques, especially in Europe. Interestingly, modern alternative approaches cover the application of biostimulants in promoting plant growth or the enhancement of a plant root system interaction with the soil bacteria and arbuscularmycorrhizal fungi.

Foliar and soil fertilization: Foliar fertilization is based on the application of nutrients directly on the plants leaves. Absorption occur either via cuticular or via stomatal pathway (Fernández and Eichert 2009, Fernández and
Brown 2013). Nutrient absorption via stomata can be further enhanced by using surfactants (Field and Bishop 1988). Recently, nutrients in the form of microparticles $(<4 \mu \mathrm{m})$ were launched on the market. These are expected to have improved ability to be absorbed and utilized in the plant tissues. Kaiser et al. (2014) reported that application with surfactant improves absorption of microparticles by stomatal pathway. Mobility of compounds within the plant tissues is of great importance, because it improves utilization of nutrient applied. Fageria et al. (2009) concluded that there existed large differences among plants species in ability to remobilize different nutrients. Ali et al. (2017) revealed that selenate is a more mobile form of selenium in the soil than selenite; therefore, it is a more appropriate form of selenium for root uptake. One study utilizing stable isotopes of selenium showed that selenite is metabolized in the root into both high- and lowmolecular mass compounds of low mobility for transport to the leaves whereas selenate is accumulated in the leaves (Di Tullo et al. 2015). Importantly, results showed that 


\begin{tabular}{|c|c|c|}
\hline BIOFORTIFICATION & & \\
\hline \multirow[t]{3}{*}{$\begin{array}{l}\text { FERTILIZATION-BASED } \\
\text { STRATEGIES }\end{array}$} & $\begin{array}{c}\text { DIRECT APPLICATION OF } \\
\text { NUTRIENT }\end{array}$ & $\begin{array}{l}\text { Application of nutrients onto } \\
\text { leaves or directly into } \\
\text { substrate (soil, hydroponic } \\
\text { culture, etc.). }\end{array}$ \\
\hline & $\begin{array}{l}\text { ENHANCEMENT OF } \\
\text { GROWTH }\end{array}$ & $\begin{array}{l}\text { Treatment of plant with } \\
\text { biostimulants. }\end{array}$ \\
\hline & $\begin{array}{c}\text { SUPPORT OF } \\
\text { ROOT } \leftrightarrow \text { MICROORGANISM } \\
\text { INTERACTION }\end{array}$ & $\begin{array}{l}\text { Treatment of seeds with } \\
\text { beneficial microorganisms. }\end{array}$ \\
\hline \multirow[t]{3}{*}{$\begin{array}{l}\text { BIOTECHNOLOGICAL } \\
\text { STRATEGIES }\end{array}$} & $\begin{array}{l}\text { IDENTIFICATION AND } \\
\text { INTRODUCING OF NEW } \\
\text { TRAITS }\end{array}$ & $\begin{array}{l}\text { Comparison of contrasting } \\
\text { genomes (Genome wide } \\
\text { association study). } \\
\text { Crossing and selection of } \\
\text { traits (Marker-assisted } \\
\text { selection). }\end{array}$ \\
\hline & $\begin{array}{l}\text { MODIFICATION OF } \\
\text { TRANSPORT AND } \\
\text { METABOLIC PATHWAYS }\end{array}$ & \multirow{2}{*}{$\begin{array}{c}\text { Plant Agrobacterium-mediated } \\
\text { or biolistic transformation. } \\
\text { Enhancement of transport or } \\
\text { biosynthesis of desirable } \\
\text { substance. } \\
\text { Restriction of metabolization } \\
\text { and degradation of desirable } \\
\text { substance. } \\
\text { Metabolomic analysis of } \\
\text { intermediates. } \\
\text { Anther cultures for transgene } \\
\text { stabilization. }\end{array}$} \\
\hline & $\begin{array}{c}\text { CREATION OF } \\
\text { BIOSYNTHETIC PATHWAYS } \\
\text { DE NOVO }\end{array}$ & \\
\hline
\end{tabular}

Fig 1. Biofortification strategies.

the form and concentration of the microelement is crucial to achieve optimal biofortification without negative effects. For instance, $\mathrm{IO}_{3}{ }^{-}$applied to strawberries cause nitrate accumulation, thus reducing food quality (Li et al. 2017). Similarly, as in the case of iodine, the form and concentration of selenium applied onto plants is critical although it seems to be species-dependent. Application of selenate at a concentration of $5 \mu \mathrm{M}$ results in increased accumulations of magnesium, zinc, and manganese in maize, whereas the combined application of selenite and selenate cause a fall off cation accumulations. Additionally, selenite alone induces a reduction in the production of plant biomass (Longchamp et al. 2016). In contrast, application of a selenite/selenate mixture at a concentration of $5 \mu \mathrm{M}$ exhibits a positive effect on the root and stalk production in wheat (Boldrin et al. 2016). Overall, effectiveness of fertilization based strategy as a mean of biofortification have to be considered when it comes to quantification of costs. Interestingly, Wang et al. (2016) evaluated the foliar application of $\mathrm{Zn}$ combined with pesticide and concluded that this approach is economically cost-effective and sustainable. However, particularly in the case of zinc, results of the field experiment demonstrated that the enhancement of zinc requires optimal phosphate management in addition to zinc fertilization (Zhang et al. 2015).

Biostimulants and symbiotic microorganisms: An attractive approach of crop biofortification consists in the utilization of biostimulants - chemical substances possessing biological activity, which facilitates the uptake and storage of microelements or biomass production. Billard et al. (2014) tested in a hydroponic culture system two substances AZAL5 and HA7 on rapeseed that do not actually improve microelement uptake, but they induce root formation and so $\mathrm{N}, \mathrm{S}, \mathrm{K}$, and $\mathrm{P}$ uptake. Also, an increased rate of $\mathrm{Fe}$ and $\mathrm{Zn}$ root-to-shoot translocation was observed in the treated plants. Substances derived from amino acids (AA) constitute an important group of biostimulants. Their foliar application can improve acquisition of microelements (Kałużewicz et al. 2018, Popko et al. 2018). Modification of sugar content can be strengthened using commercial biostimulants such as Asahi SL and Kelpak SL (Zarzecka and Gugała 2018). Another group of plant biostimulants constitute plant growth regulators and their derivatives that participate in various cell and morphological processes. Interestingly, an experimentally developed cytokinin derivative $2-\mathrm{Cl}$ 3-MeOBAP has been extensively tested in the field conditions and exhibits a positive effect on the number of productive tillers and improvement of grain filling leading to homogeneity of the spike (Koprna et al. 2016).

A promising approach for crop biofortification also lies in a better interaction of the root system and soil microorganisms. Soil bacteria and fungi are capable of the transformation of insoluble compounds into easily soluble 
forms, which can be absorbed by plants. Moreover, it has been reported that endophytic bacteria are capable of plant growth enhancement even by means of plant hormone production (Rohini et al. 2017). Hence, improvements of the nutritional characteristics of arable crops could be achieved by refining interactions between plants and soil microorganisms. Higher biomass production, an abundance of vitamin B1 and its analogs, and increased content of organic acids have all been achieved by the inoculation of plant seeds with the arbuscular-mycorrhizal fungus Rhizopagus irregularis (Rozpadek et al. 2016). Similarly, the zinc solubilizing bacterium Exiguobacterium aurantiacum has been described and used to induce up to a 6-fold elevation in zinc content (Shaikh and Saraf 2017).

\section{Biotechnological approaches}

Biotechnology approaches utilize promptly achievements of scientific progress. Description of metabolic pathways and their regulation enables scientists to start thinking about modification or altering such pathways in order to increase content of desirable substances or minerals. Further, development of whole new biosynthetic pathways in host organisms entered the new possibilities of biotechnological approaches. Biotechnological strategy covers classical breeding techniques supplemented by marker assisted selection (MAS) and advanced methods of genetic engineering [gene over-expression, silencing by RNA interference (RNAi) technology, or the direct knockingout of genes using the tools of genome editing]. Especially advanced biotechnological approaches depend on a good grasp of the basic research, e.g., genes and enzymes involved in the synthesis, transport, and accumulation of the substances studied. Further, knowledge of gene sequences, regulatory pathways, cell signaling, enzyme biochemistry, and the phenotypic consequences of genetic manipulation are a precondition for biotechnological manipulation. In the case of heterologous expression, the choice of appropriate promoters and sequence optimization for a given organism need to be considered before any realization of the transformation experiment. Afterwards, the arrangement of diverse genetic sources (i.e., alternative genes, promoters, and terminators that might be exploitable for the biofortification) is of great importance.

Conventional biotechnology approach: Conventional biotechnology that utilizes MAS has become a part of breeding process of staple crops. It depends on identification of traits of interest that can be introduced into new elite cultivars. The differential comparison of staple crops, differences in the content of studied elements or substances by bioinformatic, transcriptomic, proteomic, and various analytical methods are capable of generating data relevant for the evaluation of new traits responsible for production and accumulation of desired substances. Initial efforts made in the field of biotechnology started with utilization of MAS (Paterson et al. 1988). Marker assisted selection could be considered as a reliable and robust technique that facilitates breeding and selection of suitable genotypes. It is utilized routinely in conventional breeding programs. Additionally, to identify traits with minor effect, MAS based on genomic selection (GS-MAS) could be exploited, and markers derived from such traits can be used later in selection (Meuwissen et al. 2001).

Methods mentioned above were used for enhancement of microelement content in mature seeds as microelements constitute a substantial part of the nutritional value of the plant seed. Once absorbed, the microelements are transported into vegetative tissues. Lately, microelements are transported into the developing seeds, where they can be also remobilized from other plant tissues. Identification of those traits responsible for the remobilization of microelements from the vegetative to the generative tissues is crucial. Hussain et al. (2016) mapped quantitative trait locus (QTL) in barley associated with $\mathrm{Zn}$ remobilization from the leaves to grains. The study revealed that there is a significant variability in plant ability to translocate microelements to grains, for instance barley cv. Sahara is able to remobilize almost $40 \%$ of Zn. Similarly, CrespoHerrera et al. (2016) identified QTL at wheat chromosome 4BS, which is responsible for one-fifth of $\mathrm{Zn}$ content variability in grains. Metal tolerance proteins, which are predominantly expressed in the cells of the aleurone layer, are engaged in the regulation of elemental deposition. Generally, the accumulation of microelements in the grain is affected by genotype. It has been proven that distinct rice genotypes can differ in their mean $\mathrm{Zn}$ deposition and if either translocation from the leaves or transport from the roots prevails (Johnson-Beebout et al. 2016).

Modification of pathways: A breaking point of biotechnology was discovery and application of Agrobacterium-mediated plant transformation (Schell and Van Montagu 1977). Lately, biolistic transformation was introduced as a suitable technique (Sanford 1990) and together with the Agrobacterium-mediated transformation became the most expanded techniques of plant genetic manipulation. Genetic modifications can be exploited for tailoring plant cell transport and synthetic or metabolizing pathways in order to increase microelement, vitamin, or FA content.

Initially, single or multiple gene over-expressions were used to modulate biochemical pathways. In plants, complex-forming organic molecules, such as nicotianamine and citrate, play a role in the translocation and transport of microelements. Therefore, research is focused on enhancement of microelement transport via increased production of microelement binding molecules such as nicotianamine. Both, non-specifically induced expression of nicotianamine synthase $(N A S)$ in rice (Lee et al. 2011) and specifically over-expressed OsNAS or $O s N A S 2$ in the phosphate poor endosperm of rice (Johnson et al. 2011) and wheat (Singh et al. 2017) result in a considerable increase of $\mathrm{Zn}$ content. In the case of localized expression in developing grains, concomitant $\mathrm{Fe}$ enrichment in grains of rice and wheat is also observed (Johnson et al. 2011, Singh et al. 2017). Additionally, in order to improve Fe content in grains, over-expression of 
$N A S$ is coupled with over-expression of iron transporters and ferritin (Boonyaves et al. 2017).

Extensive research has been conducted on the topic of seed FA composition. Unfortunately, over-production of enzymes associated with transport or synthesis of desired substance is occasionally accompanied with negative phenotypic manifestations. For instance, Braybrook et al. (2006) reported that FA biofortification through constitutive expression of genes from the biosynthetic pathway result in some cases in growth and developmental anomalies. Maximization of FA content in seeds could not only lead to negative phenotypic manifestations but also to reaching the physiological limits of the organism. One solution could be the conversion of saturated into unsaturated FAs. Therefore, Du et al. (2016) employed RNAi technology to silence the stearoyl-acyl carrier protein desaturase-1 (SAD1), the enzyme that catalyzes conversion of the stearoyl-acyl carrier protein (ACP) to oleoyl-ACP, which is a precursor of polyunsaturated FAs. A lowered activity of SAD1 results in an increased amount of stearic acid and other long FAs with a concomitant decrease in oleic acid content. Kim et al. (2014) suggested that enhanced triacylglycerol accumulation in seeds could be achieved by restriction of its catabolism. Silencing sugar dependent 1 lipase, participating in the catabolism of FA, caused up to a $30 \%$ higher content of total seed storage lipids along with a $7 \%$ decrease in protein content. Quality of FA is enhanced by seed-specific silencing $F A$ dehydrogenase 2 (FAD2) and/or a FA elongase 1 (FAE1). Especially, concomitant depression of FAD2 and FAE1 leads into an extreme ratio of different $\mathrm{C} 18$ unsaturated FAs, thus improving seed nutritional quality (Shi et al. 2017). Biofortification of desirable substance, such as AAs or vitamins, might be achieved via restriction of metabolizing pathways rather than boosting production by gene over-expression. Hence, new techniques that allow a more precise manipulation with genome and gene transcriptions, are adapted. Aminoacids, especially essential, such as lysine, methionine, threonine, and phenylalanine, have also been subjects of biofortification. Sikdar et al. (2016) used RNAi technology to reduce a storage C-hordein protein by up to $97 \%$. Concomitantly, a drop in C-hordein content is balanced by an increase in B-hordein. Noticeably, a decrease in C-hordein positively affects the content of the essential AAs threonine, methionine, and leucine. Thus, RNAi technology could assist a successful development of low hordein lines and enrichment of essential compounds.

Aside from gene transcription silencing, modification of biochemical pathways can be alternatively performed via new mutagenesis by using programmable nucleases, such as transcription activator-like effector nuclease (TALEN) or clustered regularly interspaced short palindromic repeats (CRISPR)/CRISPR-associated 9 (Cas9) (Jinek et al. 2012), that enables precise genomic alterations. Classical mutagenesis still has its place among other techniques. Development of a mutant by fast neutron irradiation was evidence for mutagenesis. Increased content of lipidsoluble antioxidants, such as vitamin E, could be achieved by single knock-out of homogentisate dioxygenase
(HGO1). A mutation in this gene also causes tolerance to herbicides targeting homogentisate metabolism (Stacey et al. 2016). However, usage of programmable nucleases has several unique advantages such as a predicted mutated locus that does not have to be mapped, avoiding work with a mutant population, and ability to create mutations in homozygous constitution in the $\mathrm{T}_{0}$ generation. The presence of these drawbacks in classical mutagenesis predicts a bright future for using a molecular biology tool such as CRISPR/Cas9 or TALEN. For example, a critical qualitative parameter for grain evaluation is the stability of unsaturated FAs after harvest. Degradation of FAs as a consequence of oxidation occurs to a large extent. Lipoxygenases, which catalyze dioxygenation, contribute significantly to the degradation of FAs. Hydroperoxide, as a product of the reaction, constitutes an important factor in the durability and viability of seeds. Using TALEN, Ma et al. (2015) developed a rice mutant in lipoxygenase lox3. Knock-out of this gene reduces FA oxidation in longterm stored rice grains and has no unfavorable effect on the performance of its agronomic traits. An indisputable advantage of programmable nucleases appears when crops with polyploid genomes are subjected to genetic manipulation. Efficiency of CRISPR/Cas9 nuclease was demonstrated on the allohexaploid Camelina sativa containing three alleles of FA elongase 1 genes FAE1, when all three alleles are knocked-out in homozygous constitution in a single generation resulting in an almost total restriction of production of very long-chain FAs (Ozseyhan et al. 2018). Similarly, the precision of genome editing by Cas 9 nuclease was also demonstrated producing knock-out in the FAD2 gene in C. sativa (Jiang et al. 2017) or OsFAD2-1 gene in rice (Abe et al. 2018) leading to alteration of the content of oleic acid in the mutant lines. For instance in C. sativa, the content of oleic acid rises from 16 to $50 \%$, and production of monounsaturated FA rises by $44 \%$.

De novo pathway development: Wide knowledge of metabolic processes is a precondition for development of plants with engineered synthetic pathways. Such a strategy can be considered as advanced pathway modification. For sustainable production of a specific substance, key enzymes have to be identified. De novo created synthetic pathway requires, apart from key enzymes, also basal precursors of the desired substance, whose production is expected. Such a premise was recently integrated into development of transgenic sorghum. Che et al. (2016) prepared transgenic sorghum over-expressing $\beta$-carotene synthesizing enzymes, in a manner similar to that in golden rice (Paine et al. 2005). In addition they inserted a gene coding for 1-deoxyxylulose 5-phosphate synthase, a rate-limiting enzyme in the methylerythritol phosphate pathway, thereby increasing the availability of a precursor for carotenoid biosynthesis. Alterations in the amounts of intermediates and the restriction of their further metabolism may occur when new biosynthetic pathways are being constructed in planta. Such issues need to be considered when designing strategies for production of $\omega 3$-long-chain polyunsaturated FA in model plant species. (Qi et al. 2004) 
and Camelina sativa (Ruiz-Lopez et al. 2014). Production of polyunsaturated FAs in above mentioned works was achieved by over-expression of 5 or 7 transgenes for eicosapentaenoic acid (20:5, n-3) and docosahexaenoic acid (22:6, n-3), respectively. Biosynthesis is streamlined by introducing an acyl CoA-dependent $\Delta 6$-desaturase from Ostrococcus tauri (Domergue et al. 2005) that enables accumulation of eicosapentaenoic acid and prevents undesirable accumulation of $\mathrm{C} 18$ biosynthetic intermediates (Sayanova et al. 2012, Ruiz-Lopez et al. 2013) thus depicting the importance of characterization of metabolome and a need of detailed metabolic evaluation of intermediates and their changes as a result of transgene integration. Similar obstacles have to be solved when lysine biofortified rice is prepared (Long et al. 2013, Yang et al. 2016). A transgenic line producing up to 25 -fold higher content of lysine than the wild type was developed by boosting its synthesis via DAPA and LYSC over-expression and by crucial down-regulation of lysine metabolizing enzymes lysine ketoglutarate reductase (LKR) and saccharopine dehydrogenase (SDH) and thus catabolism of accumulated lysine into 2-oxoadipate. Notably, agronomic evaluations of plants suggested that significantly increased content of lysine only slightly affects plant height (Yang et al. 2016).

In almost all cases, novel traits produced by the biotechnological approaches discussed in this review will need to be crossed into high-yielding cultivars. However, such a process might be complicated by selecting an appropriate background genotype. The genetic background of the recipient cultivar should be carefully chosen in order to obtain the desired phenotypic manifestation. For instance, a better phenotypic manifestation is achieved when Oryza sativa gene $N A S$ in the donor rice cv. Nipponbare (subspecies japonica) is introduced into a rice cultivars from the subspecies japonica rather than into those from subspecies indica (Moreno-Moyano et al.2016). Therefore, selection of a suitable genetic background of the acceptor cultivar, which has none (or a minor) impact on the manifestation of the trait, is of importance. Moreover, the homozygous make up of a target trait is often required in the breeding process. Notably, production of doubledhaploids could reduce the time needed for stabilization of the transgene in the genome, and then could be used in the functional validation of the gene and subsequent crossing (Shen et al. 2015).

Interestingly, concerning practical testing of vitamin A content in feed showed that an increased uptake of carotenoids has a positive effect on the tested subjects. Nogareda et al. (2016) proved not only that broilers fed with transgenic maize producing increased amount of carotenoids are able to acquire carotenoids better than from additives, but that the carotenoid diet delays the reproductive cycle of the protozoan parasite E. tenella, the cause of coccidiosis. Vitamin A biofortified rice was assessed as a food additive in the diet of Ethiopian children. If consumed as a staple part of the diet, the consummation of this rice was an effective source of vitamin A. There were no cases of hypervitaminosis noted in the group consuming the biofortified rice whereas hypervitaminosis cases were in the artificially produced food additive group (Gannon et al. 2014).

\section{Concluding remarks}

Fertilization-based and biotechnological ways of plant biofortification are feasible and capable of increasing the content of important substances in plants. These advanced techniques, such as the use of microparticles for the foliar application of nutrients, the development of sophisticated molecular biology tools for precise genome manipulation, or the introduction of complete metabolic pathways, provide effective biofortification strategies. These approaches, which are proving attractive to farmers, have undergone substantial progress. The decision on which approach to use will depend on the legislative, financial, and practical options available to the producer. New molecular biology techniques, such as TALEN or CRISPR/Cas9 have been promptly implemented and can be expected to play an important role in production of biofortified crops in the future.

\section{References}

Abe, K., Araki, E., Suzuki, Y., Toki, S., Saika, H.: Production of high oleic/low linoleic rice by genome editing. - Plant Physiol. Biochem. 131: 58-62, 2018.

Ali, F., Peng, Q., Wang, D., Cui, Z., Huang, J., Fu, D., Liang, D.: Effects of selenite and selenate application on distribution and transformation of selenium fractions in soil and its bioavailability for wheat (Triticum aestivum L.). - Environ. Sci. Pollut. Res. 24: 8315-8325, 2017.

Billard, V., Etienne, P., Jannin, L., Garnica, M., Cruz, F., GarciaMina, J.M., Yvin, J.C., Ourry, A.: Two biostimulants derived from algae or humic acid induce similar responses in the mineral content and gene expression of winter oilseed rape (Brassica napus L.). - J. Plant Growth Regul. 33: 305-316, 2014.

Blancquaert, D., Van Daele, J., Strobbe, S., Kiekens, F., Storozhenko, S., De Steur, H., Gellynck, X., Lambert W., Stove Ch., Van Der Straeten, D.: Improving folate (vitamin B9) stability in biofortified rice through metabolic engineering. Nat. Biotech. 33: 1076-1078, 2015.

Boldrin, P.F., De Figueiredo, M.A., Yang, Y., Luo, H., Giri, S., Hart, J.J., Faquin, V., Guilherme, L.R.G., Thannhauser, T.W., Li, L.: Selenium promotes sulfur accumulation and plant growth in wheat (Triticum aestivum). - Physiol. Plant. 158: 80-91, 2016.

Boonyaves, K., Wu, T.Y., Gruissem, W., Bhullar, N.K.: Enhanced grain iron levels in rice expressing an iron-regulated metal transporter, nicotianamine synthase, and ferritin gene cassette. - Front. Plant Sci. 8: 1-11, 2017.

Bouis, H.E.: Plant breeding: a new tool for fighting micronutrient malnutrition. - J. Nutr. 132: 491S-494S, 2002.

Braybrook, S.A., Stone, S.L., Park, S., Bui, A.Q., Le, B.H., Fischer, R.L., Goldberg, R.B., Harada, J.J.: Genes directly regulated by leafy cotyledon 2 provide insight into the control of embryo maturation and somatic embryogenesis. - Proc. nat. Acad. Sci. USA 103: 3468-3473, 2006.

Che, P., Zhao, Z., Glassman, K., Dolde, D., Hu, T.X., Jones, T.J., Obukosia, S., Wambugu, F., Che, P., Zhao, Z., Glassman, K., Dolde, D., Hu, T.X., Jones, T.J., Fred, D.: Elevated vitamin 
E content improves all-trans $\beta$-carotene accumulation and stability in biofortified sorghum. - Proc. nat. Acad. Sci. USA 113: 11040-11045, 2016.

Crespo-Herrera, L.A., Velu, G., Singh, R.P.: Quantitative trait loci mapping reveals pleiotropic effect for grain iron and zinc concentrations in wheat. - Ann. appl. Biol. 169: 27-35, 2016.

Di Tullo, P., Versini, A., Bueno, M., Le Hécho, I., Thiry, Y., Biron, P., Castrec-Rouelle, M., Pannier, F.: Stable isotope tracing: A powerful tool for selenium speciation and metabolic studies in non-hyperaccumulator plants (ryegrass Lolium perenne L.). Anal. bioanal. Chem. 407: 9029-9042, 2015.

Domergue, F., Abbadi, A., Zähringer, U., Moreau, H., Heinz, E.: In vivo characterization of the first acyl-CoA delta6desaturase from a member of the plant kingdom, the microalga Ostreococcus tauri. - Biochem. J. 389: 483-490, 2005.

Du, H., Huang, M., Hu, J., Li, J.: Modification of the fatty acid composition in Arabidopsis and maize seeds using a stearoylacyl carrier protein desaturase-1 (ZmSAD1) gene. - BMC Plant Biol. 16: 137, 2016.

Fageria, N.K., Filho, M.P.B., Moreira, A., Guimarães, C.M.: Foliar fertilization of crop plants. - J. Plant Nutr. 32: 10441064, 2009.

Fernández, V., Brown, P.H.: From plant surface to plant metabolism: the uncertain fate of foliar-applied nutrients. Front. Plant Sci. 4: 1-5, 2013.

Fernández, V., Eichert, T.: Uptake of hydrophilic solutes through plant leaves: current state of knowledge and perspectives of foliar fertilization. - Crit. Rev. Plant Sci. 28: 36-68, 2009.

Field, R.J., Bishop, N.G.: Promotion of stomatal infiltration of glyphosate by an organosilicone surfactant reduces the critical rainfall period. - Pestic. Sci. 24 :55-62, 1988.

Gannon, B., Kaliwile, C., Arscott, S.A., Schmaelzle, S., Chileshe, J., Kalungwana, N., Mosonda, M., Pixley, K., Masi, C., Tanumihardjo, S.A.: Biofortified orange maize is as efficacious as a vitamin A supplement in Zambian children even in the presence of high liver reserves of vitamin A: a community-based, randomized placebo-controlled trial. Amer. J. clin. Nutr. 100: 1541-1550, 2014.

Hussain, S., Rengel, Z., Mohammadi, S.A., Ebadi-Segherloo, A., Maqsood, M.A.: Mapping QTL associated with remobilization of zinc from vegetative tissues into grains of barley (Hordeum vulgare). - Plant Soil 399: 193-208, 2016.

Jiang, W.Z., Henry, I.M., Lynagh, P.G., Comai, L., Cahoon, E.B., Weeks, D.P.: Significant enhancement of fatty acid composition in seeds of the allohexaploid, Camelina sativa, using $C R I S P R / C a s 9$ gene editing. - Plant Biotechnol. J. 15: 648-657, 2017.

Jinek, M., Chylinski, K., Fonfara, I., Hauer, M., Doudna, J., Charpentier, E.: A programmable dual-RNA - guided DNA endonuclease in adaptive bacterial immunity. - Science 337: 816-822, 2012.

Johnson, A.A.T., Kyriacou, B., Callahan, D.L., Carruthers, L., Stangoulis, J., Lombi, E., Tester, M.: Constitutive overexpression of the OsNAS gene family reveals single-gene strategies for effective iron- and zinc-biofortification of rice endosperm. - Plos ONE 6: e24476, 2011.

Johnson-Beebout, S.E., Goloran, J.B., Rubianes, F.H.C., Jacob, J.D.C., Castillo, O.B.: Zn uptake behavior of rice genotypes and its implication on grain $\mathrm{Zn}$ biofortification. - Sci. Rep. 6: 38301, 2016.

Kaiser, H.: Stomatal uptake of mineral particles from a sprayed suspension containing an organosilicone surfactant. - J. Plant Nutr. Soil Sci. 177: 6, 869-874, 2014.

Kałużewicz, A., Bosiacki, M., Spiżewski, T.: Influence of biostimulants on the content of macro- and micronutrients in broccoli plants exposed to drought stress. - J. Elements 23:
287-297, 2018.

Kim, M.J., Yang, S.W., Mao, H.Z., Veena, S.P., Yin, J.L., Chua, N.H.: Gene silencing of sugar-dependent 1 (JcSDP1), encoding a patatin-domain triacylglycerol lipase, enhances seed oil accumulation in Jatropha curcas. - Biotechnol. Biofuels 7: 36, 2014.

Koprna, R., De Diego, N., Dundálková, L., Spíchal, L.: Use of cytokinins as agrochemicals. - Bioorganic med. Chem. 24: 484-492, 2016.

Lee, S., Persson, D.P., Hansen, T.H., Husted, S., Schjoerring, J.K., Kim, Y.S., Jeon, U.S., Kim, Y.K., Kakei, Y., Masuda, H., Nishizawa, N.K., An, G.: Bio-available zinc in rice seeds is increased by activation tagging of nicotianamine synthase. Plant Biotechnol. J. 9: 865-873, 2011.

Li, R., Liu, H.P., Hong, C.L., Dai, Z.X., Liu, J.W., Zhou, J., Hu, C.Q., Weng, H.X.: Iodide and iodate effects on the growth and fruit quality of strawberry. - J. Sci. Food Agr. 97: 230$235,2017$.

Long, X., Liu, Q., Chan, M., Wang, Q., Sun, S.S.M.: Metabolic engineering and profiling of rice with increased lysine. - Plant Biotechnol. J. 11: 490-501, 2013.

Longchamp, M., Angeli, N., Castrec-Rouelle, M.: Effects on the accumulation of calcium, magnesium, iron, manganese, copper and zinc of adding the two inorganic forms of selenium to solution cultures of Zea mays. - Plant Physiol. Biochem. 98: $128-137,2016$.

Ma, L., Zhu, F., Li, Z., Zhang, J., Li, X., Dong, J., Wang, T.: TALEN-based mutagenesis of lipoxygenase LOX3 enhances the storage tolerance of rice (Oryza sativa) seeds. - Plos ONE 10: e0143877, 2015.

Meuwissen, T.H.E., Hayes, B.J., Goddard, M.E.: Prediction of total genetic value using genome-wide dense marker maps. Genetics 157: 1819-1829, 2001.

Moreno-Moyano, L.T., Bonneau, J.P., Sánchez-Palacios, J.T., Tohme, J., Johnson, A.A.T.: Association of increased grain iron and zinc concentrations with agro-morphological traits of biofortified rice. - Front. Plant Sci. 7: 1463, 2016.

Nogareda, C., Moreno, J.A., Angulo, E., Sandmann, G., Portero, M., Capell, T., Zhu, C., Christou, P.: Carotenoid-enriched transgenic corn delivers bioavailable carotenoids to poultry and protects them against coccidiosis. - Plant Biotechnol. J. 14: 160-168, 2016.

Ozseyhan, M.E., Kang, J., Mu, X., Lu, C.: Mutagenesis of the FAE1 genes significantly changes fatty acid composition in seeds of Camelina sativa. - Plant Physiol. Biochem. 123: 1-7, 2018.

Paine, J.A., Shipton, C.A., Chaggar, S., Howells, R.M., Kennedy, M.J., Vernon, G., Wright, S.Y., Hinchliffe, E., Adams, J.L., Silverstone, A.L., Drake, R.: Improving the nutritional value of Golden rice through increased pro-vitamin A content. - Nat. Biotech. 23: 482-487, 2005.

Paterson, A.H., Lander, E.S., Hewitt, J.D., Peterson, S., Lincoln, S.E., Tanksley, S.D.: Resolution of quantitative traits into Mendelian factors by using a complete linkage map of restriction fragment length polymorphisms. - Nature 335: 721-726, 1988.

Paul, J.Y., Khanna, H., Kleidon, J., Hoang, P., Geijskes, J., Daniells, J., Zaplin, E., Rosenberg, Y., James, A., Mlalazi, B., Deo, P., Arinaitwe, G., Namanya, P., Becker, D., Tindamanyire, J., Tushemereirwe, W., Harding, R., Dale, J.: Golden bananas in the field: elevated fruit pro-vitamin A from the expression of a single banana transgene. - Plant Biotechnol. J. 15: 520532, 2017.

Popko, M., Michalak, I., Wilk, R., Gramza, M., Chojnacka, K., Górecki, H.: Effect of the new plant growth biostimulants based on amino acids on yield and grain quality of winter 
wheat. - Molecules 23: 470, 2018.

Qi, B., Fraser, T., Mugford, S., Dobson, G., Sayanova, O., Butler, J., Napier, J.A., Stobart, A.K., Lazarus, C.M.: Production of very long chain polyunsaturated omega- 3 and omega- 6 fatty acids in plants. - Nat. Biotech. 22: 739-745, 2004.

Rohini, S., Aswani, R., Kannan, M., Sylas, V.P., Radhakrishnan, E.K.: Culturable endophytic bacteria of ginger rhizome and their remarkable multi-trait plant growth-promoting features. - Curr. Microbiol. 75: 505-511, 2017.

Rozpadek, P., Rapała-Kozik, M., Wezowicz, K., Grandin, A., Karlsson, S., Wazny, R., Anielska, T., Turnau, K.: Arbuscular mycorrhiza improves yield and nutritional properties of onion (Allium cepa). - Plant Physiol. Biochem. 107: 264-272, 2016.

Ruiz-Lopez, N., Haslam, R.P., Napier, J.A., Sayanova, O.: Successful high-level accumulation of fish oil omega-3 longchain polyunsaturated fatty acids in a transgenic oilseed crop. - Plant J. 77: 198-208, 2014.

Ruiz-Lopez, N., Haslam, R.P., Usher, S.L., Napier, J.A., Sayanova, O.: Reconstitution of EPA and DHA biosynthesis in Arabidopsis: iterative metabolic engineering for the synthesis of n-3 LC-PUFAs in transgenic plants. - Metabol. Eng. 17: 30-41, 2013.

Sanford, J.C.: Biolistic plant transformation. - Physiol. Plant. 79: 206-209, 1990.

Sayanova, O., Ruiz-Lopez, N., Haslam, R.P., Napier, J.A.: The role of $\Delta 6$-desaturase acyl-carrier specificity in the efficient synthesis of long-chain polyunsaturated fatty acids in transgenic plants. - Plant Biotechnol. J. 10: 195-206, 2012.

Schell, J., Van Montagu, M.: Transfer, maintenance, and expression of bacterial Ti-plasmid DNA in plant cells transformed with A. tumefaciens. - Brookhaven Symp. Biol. 29: 36-49, 1977.

Shaikh, S., Saraf, M.: Biofortification of Triticum aestivum through the inoculation of zinc solubilizing plant growth promoting rhizobacteria in field experiment. - Biocatal. agr. Biotechnol. 9: 120-126, 2017.

Shen, Y., Pan, G., Lübberstedt, T.: Haploid strategies for functional validation of plant genes. - Trends Biotechnol. 33: 611-620, 2015.

Shi, J., Lang, C., Wang, F., Wu, X., Liu, R., Zheng, T., Zhang, D., Chen, J., Wu, G.: Depressed expression of FAE1 and FAD2 genes modifies fatty acid profiles and storage compounds accumulation in Brassica napus seeds. - Plant Sci. 263: 177$182,2017$.
Sikdar, M.S.I., Bowra, S., Schmidt, D., Dionisio, G., Holm, P.B. Vincze, E.: Targeted modification of storage protein content resulting in improved amino acid composition of barley grain. - Transgenic Res. 25: 19-31, 2016.

Singh, S.P., Keller, B., Gruissem, W., Bhullar, N.K.: Rice nicotianamine synthase 2 expression improves dietary iron and zinc levels in wheat. - Theor. appl. Genet. 130: 283-292, 2017.

Stacey, M.G., Cahoon, R.E., Nguyen, H.T., Cui, Y., Sato, S., Nguyen, C.T., Phoka, N., Clark, K.M., Liang, Y., Forrester, J., Batek, J., Do, P.T., Sleper, D.A., Clemente, T.E., Cahoon, E.B., Stacey, G.: Identification of homogentisate dioxygenase as a target for vitamin e biofortification in oilseeds. - Plant Physiol. 172: 1506-1518, 2016.

Tiong, J., Mcdonald, G.K., Genc, Y., Pedas, P., Hayes, J.E., Toubia, J., Langridge, P., Huang, C.Y.: HvZIP7 mediates zinc accumulation in barley (Hordeum vulgare) at moderately high zinc supply. - New Phytol. 201: 131-143, 2014.

Uddin, M.N., Kaczmarczyk, A., Vincze, E.: Effects of $\mathrm{Zn}$ fertilization on hordein transcripts at early developmental stage of barley grain and correlation with increased $\mathrm{Zn}$ concentration in the mature grain. - PloS ONE 9: e108546, 2014.

Wang, Y.H., Zou, C.Q., Mirza, Z., Li, H., Zhang, Z.Z., Li, D.P., Xu, C.L., Zhou, X. Bin, Shi, X.J., Xie, D.T., He, X.H., Zhang, Y.Q.: Cost of agronomic biofortification of wheat with zinc in China. - Agron. sustain. Dev. 36: 44, 2016.

Yang, Q., Zhang, C., Chan, M., Zhao, D., Chen, J., Wang, Q., Li, Q., Yu, H., Gu, M., Sun, SS., Liu, Q.: Biofortification of rice with the essential amino acid lysine: molecular characterization, nutritional evaluation, and field performance. - J. exp. Bot. 67: 4285-4296, 2016.

Zarzecka, K., Gugała, M.: The effect of herbicides and soil tillage systems on the content of polyphenols in potato tubers. Polish J. environ. Stud. 64: 82-87, 2018.

Zhang, W., Liu, D., Li, C., Cui, Z., Chen, X., Russell, Y., Zou, C.: Zinc accumulation and remobilization in winter wheat as affected by phosphorus application. - Field Crops Res. 184: 155-161, 2015.

Zhu, C., Naqvi, S., Breitenbach, J., Sandmann, G., Christou, P., Capell, T.: Combinatorial genetic transformation generates a library of metabolic phenotypes for the carotenoid pathway in maize. - Proc. nat. Acad. Sci. USA 105: 18232-18237, 2008. 